\title{
A Study on the Analysis System of the Harmony Integration in Privacy Enter- prise Senior Team
}

\author{
Zhen WANG ${ }^{1}$ Wenming LI $^{2}$ Bo PANG ${ }^{3}$ \\ ${ }^{1}$ School of Economics and Management, Harbin Engineering University, China, 150001 \\ ${ }^{2}$ Qingdao University of Science and Technology, China, 266061 \\ ${ }^{3}$ School of Management, Harbin Institute of Technology, China, 150001
}

\begin{abstract}
In order to control the development of the private enterprise senior team integration, the leaders of private enterprise must build the analytical system of the harmonious integration. The author try to deeply research the structure, levels, estimating index of the system based on the harmonious theory, system theory, upper theory and the "3C" pattern (charactercourse-circumstances). Then we can devise a useful estimation-index system of the analytical work about the private enterprise senior team integration.
\end{abstract}

Keywords: private enterprise; senior team; harmonious integration; analysis of harmony

1. The necessity of establishing the analytical system of the harmonious integration of the private enterprise senior team

According to the common view about the existence of the systematic negative effect on system theory, in all sorts of enterprises including the large private enterprise the disharmonious state absolutely exists while the harmonious state is relative. Based on figure 1 we can see that the integrated state of the enterprise senior team always stays at the point " $x$ " $(\mathrm{x} \in[0,1])$ between "ideally harmonious state" and "Absolutely disharmonious state". Here, " 0 " stands for the disharmonious state.

When $\mathrm{x}$ moves to the point " 0 ", both the enterprise and its senior team will disappear; when $\mathrm{x}$ moves to the right, it seems to indicate that the senior team is raising the "harmonious degree" step by step and constantly getting closed to the goal of "harmonious integration". However, it's impossible for $\mathrm{x}$ to reach the relatively harmonious point. The reason is that if the enterprise stays in the developing state, all kinds of problems and changes in or out of it will exist all the time. Meanwhile, the removable space of $x$ will be constantly extended and the process of the harmonious integration will last longer and it's possible to occur over and again.

In order to control the development of the integration of the senior team as soon as possible, we must understand the whole Capital-Senior Human-Senior and the law and characteristics of their development. At the same time, we also need to analyze and judge where the $\mathrm{x}$ is and make it move to the right direction to get close to the ideally harmonious state of the senior team. What's more, it's necessary to establish the working program and the analytical system in the enterprise. With the help of those programs and sys-

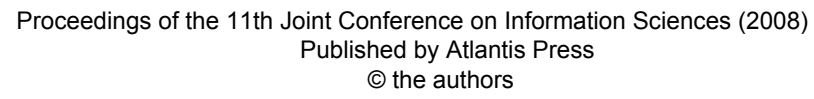




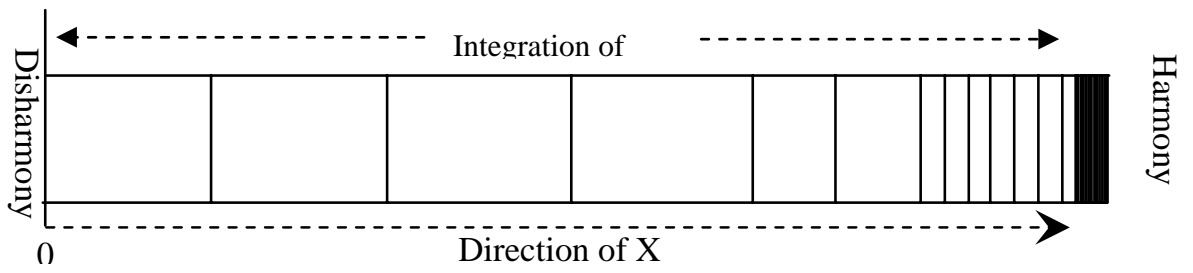

Fig. 1 the harmonious state of the enterprise senior team

tems, the following analysis was carried out:

Make a scientific evaluation and accordant judgment so that the enterprise senior team can understand its harmony degree and make the forecast and precaution against the evolvement of the disharmonious state. Finally, the enterprise can set a base for the establishment of the removable and controllable system of the harmonious integration.

2. The Model and Structure of the Analysis of the Harmonious integration of the Enterprise Senior Team

As usual, the organization structure of the enterprise senior team is unlikely never to change. Once the old stability is broken, a new stability will turn up in the following days .The changeable process of the instability is too complex to forecast, but in total, we can find out its changeable regularity and characteristics through establishing the model of the harmony system.

(I) the analysis Model of the harmonious integration of the enterprise senior team.

"The analysis of the harmonious integration of the enterprise senior team" means the research process, which was directed by the enterprise senior team and promoted by the concerned professional commission. This process also concerns whether the conditions and surroundings have been formed in which the whole team or individual show their capacity and creativity, and help each other, and whether the senior team can coordinate smoothly.

The harmonious enterprise senior team emphasizes that everyone should try their best to show their capacity and closely cooperate with each other. Furthermore, it also attaches importance to the organic interaction between human and environment. As a result, the specific index of the analysis involves the structure of the senior team members, the senior organization management, the internal atmosphere among seniors, the senior mental state, the accordant degree of their relationship, and the degree of the adaptation to the environment.

If we use the scalar function to demonstrate, the larger " $\mathrm{h}$ " is, the higher the degree of the adaptation to the environment will reach ${ }^{[1]}$. Mathematical formula to:

$$
H=h\left(h_{1}\left(\left\{p_{i}\right\}, c\right), h_{2}(e), h_{3}(u), h_{4}(a)\right)(1)
$$

where, $h_{1}\left(\left\{p_{i}\right\}, c\right)$ is the structure harmony; $h_{2}(e)$ is the organization harmony; $h_{3}(u)$ is the internal atmosphere harmony and $h_{4}(a)$ is the harmony between the senior team and the exterior circumstance; $H$ is the harmony of the whole senior team

(II) The analysis structure of the harmonious integration of the enterprise senior team based on the " $3 C$ " system.

The analysis of the harmonious integration of the enterprise senior team focuses on researching the current harmonious state $X$ (Just like the $X$ in fig.1). $X$ stands for the degree of the harmoni- 
ous integration of the enterprise senior team. Based on the view about the harmonious management theory and the system theory, the total function of the system derives from the interaction between system and environment, system and elements, elements and elements. So we can make a judgment about $X$ from three points, such as the relationship between the enterprise senior team and the environment, the whole senior team and the individual, and the interaction between all the senior members. Because the three points correspond to the circumstance, character and course of the " $3 C$ " system, we can research the harmonious state of enterprises by this " $3 C$ ” system. The specific analysis structure is just like Fig. 2 .

As we know, the analysis of the characters of the senior team emphasizes static state and aims at the structure harmony. Its contents involve senior structure, property rights and leaders' weakness. By examining these, we can judge whether the structure of senior team is harmonious and matching.

The analysis of the course of the senior team focuses on the dynamic research and attaches importance to the organization harmony analysis. Then the research content involves the decentralization and authorization among the senior team members, the team conflict, the information disproportion and the market and flat inner organization. Regarding these factors as the assessment index, we can analyze whether the efficient system structure of the enterprise senior team coinciding with the function has been built or has met the requirement of the organization harmony.

The goal of the inner circumstance analysis of the enterprise focuses on the internal harmony of the senior team. Its contents include the life cycle of the enterprise, the state of the ownership, the gross resource, the enterprise dimensions, and the organization inertia and so on.
Through analyzing those variable factors, we can estimate whether the goal, mission, wish, value, culture and so on match it and reach the realm of the inner harmony.

The analysis of the exterior circumstance focuses on the characteristics of the fiercely super-competitive environment, attaches importance to the analysis of the exterior harmony of the enterprise senior team and analyzes the harmony degree between the senior team and the exterior circumstance through studying how the senior team adapts to the characteristics of super-competitive environment.

The whole research of "CircumstanceCharacter-Course" focuses on the harmony analysis of the whole senior team. The standard of the judgment is whether the senior team and the circumstance, the whole team and individual can keep harmonious.

\section{The "3C"system based on the har- mony analysis of the private enter- prise senior team.}

Combining the analysis structure of the harmonious integration based on the "3C" system and the large private enterprise, we can establish the analysis system of the harmonious integration of the enterprise senior team. But firstly we must know the contents and all factors of the “3C"system.

(I) the identification of the private enterprise circumstances information.

The characteristics about complexion, nonlinear and uncertain result in the inner waste and conflicts in the large enterprise senior team $^{\text {[2] }}$. Just like Figure 3, its identification of the information involves two parts. One is the identification of Exterior Circumstance information (EC); the other is the identification of the Inner Circum stance(IC). There are three functions: 
General harmonious analysis

4

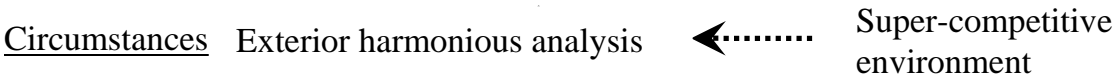

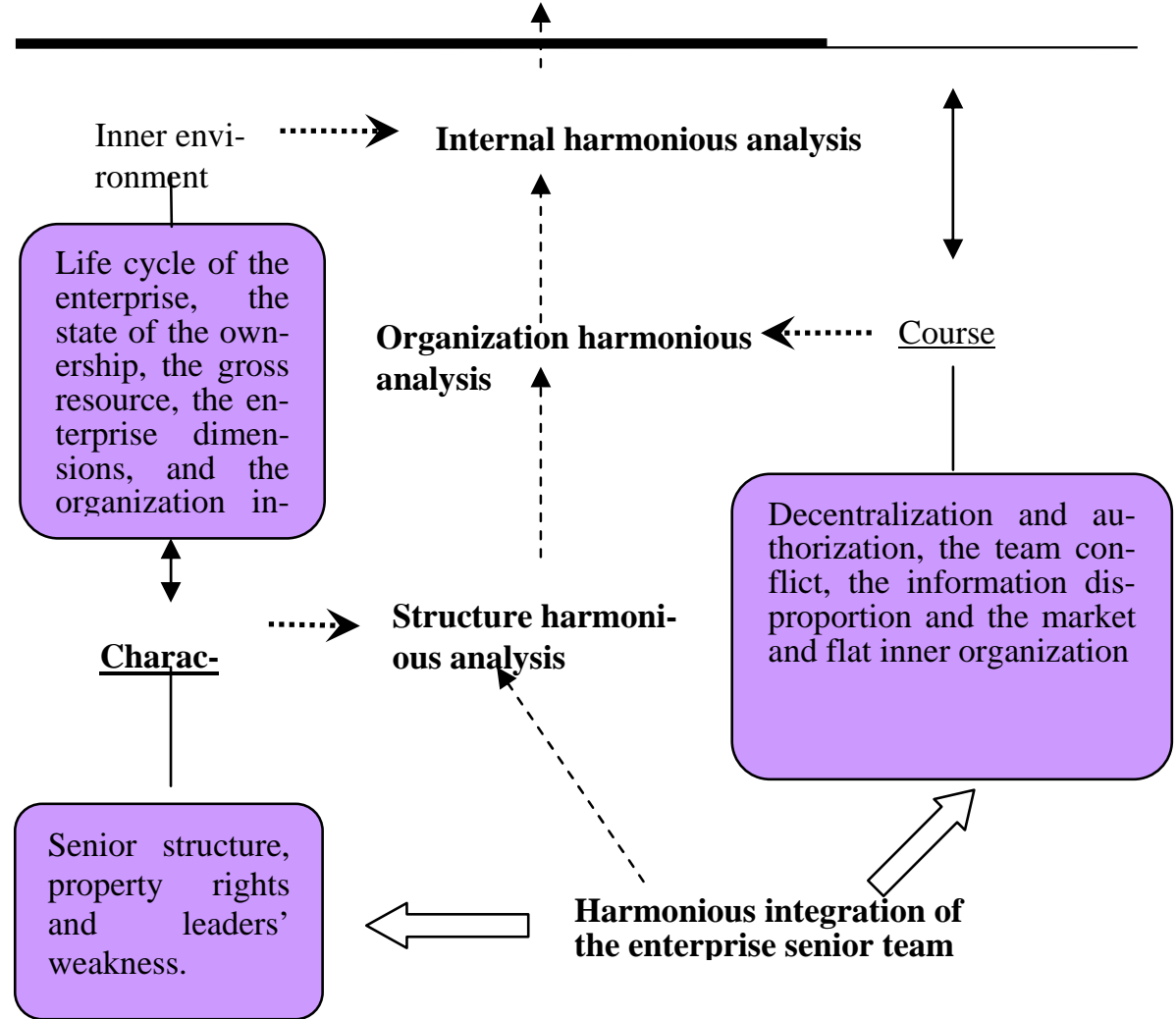

Fig. 2 the analysis system of the harmony integration based on the "3C" system

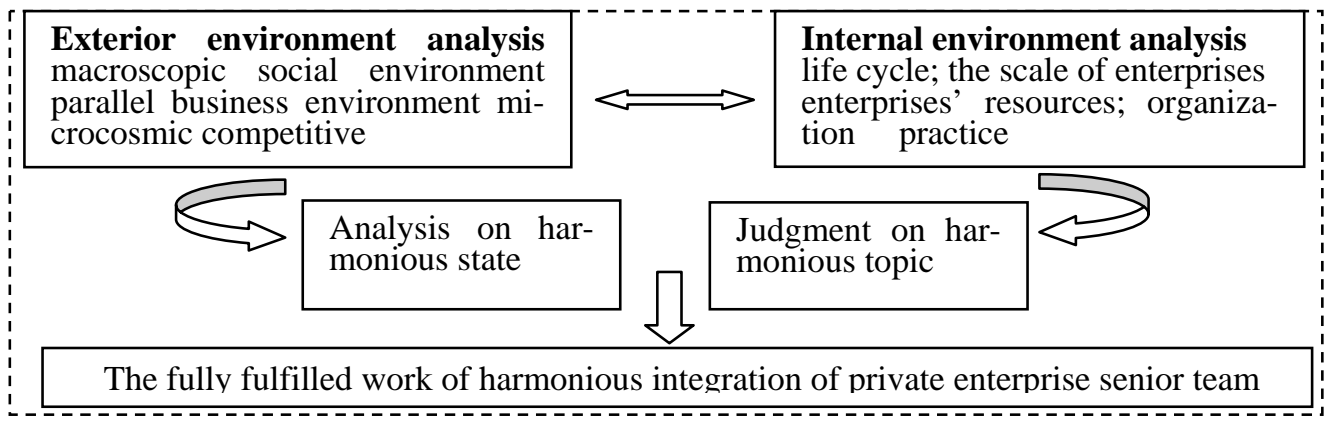

Fig.3 the identification and function of private enterprise circumstances information 
First, analyze and assess the effect on the harmonious integration of the private enterprise senior team. Second, define "the harmony theme" of the large private enterprise senior team. Third, provide information to thoroughly carry out the work of the harmonious integration of the private enterprise senior team.

(II): the analysis of enterprise senior team's characters.

The analysis of enterprise senior team's characters is an important way to study the harmony in senior team structure. By analyzing the senior team structure, property right structure and weakness structure of leaders we can comprehensively assess and judge how harmonious the senior structure is. As table 1 show, the analyses of enterprise senior team's characters are generally divided into three parts. They are senior structure; property right structure and leaders' weakness structure.

Table 1 The analysis of enterprise senior team's characters.

\begin{tabular}{|c|c|c|c|}
\hline $\begin{array}{l}\text { Analysis } \\
\text { aspects }\end{array}$ & $\begin{array}{l}\text { Senior } \\
\text { Structure }\end{array}$ & $\begin{array}{l}\text { Property right } \\
\text { Structure }\end{array}$ & $\begin{array}{l}\text { Leaders' } \\
\text { Weakness } \\
\text { Structure }\end{array}$ \\
\hline 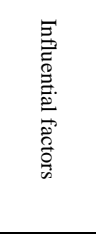 & $\begin{array}{l}\text { Age stage; } \\
\text { Educational } \\
\text { level; Career } \\
\text { background; } \\
\text { Temperament } \\
\text { Types; Presi- } \\
\text { dency; value } \\
\text { view; Insight }\end{array}$ & $\begin{array}{l}\text { Main part of } \\
\text { property } \\
\text { rights; per- } \\
\text { centage; Ad- } \\
\text { justment; } \\
\text { Ownership } \\
\begin{array}{l}\text { Structure; } \\
\text { Right's ar- } \\
\text { rangement }\end{array}\end{array}$ & $\begin{array}{l}\text { Constitution; } \\
\text { Mentality; } \\
\text { Intelligence; } \\
\text { Moral level; } \\
\text { Knowledge; } \\
\text { Endurance }\end{array}$ \\
\hline 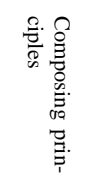 & $\begin{array}{l}\text { Reasonable } \\
\text { structure; } \\
\text { Matching } \\
\text { Conditions } \\
\text { with each other }\end{array}$ & $\begin{array}{l}\text { Planters have } \\
\text { their filed; } \\
\text { Owners should } \\
\text { manage while } \\
\text { managers own; } \\
\text { Appropriate } \\
\text { rate }\end{array}$ & $\begin{array}{l}\text { Advisable } \\
\text { exist } \\
\text { Holistic over- } \\
\text { come }\end{array}$ \\
\hline $\begin{array}{l}\text { Tै } \\
\text { 营. } \\
\text { : }\end{array}$ & $\begin{array}{l}\text { Team structure } \\
\text { is the base of } \\
\text { the foundation } \\
\text { of the private } \\
\text { enterprise } \\
\text { senior team's } \\
\text { setting up, } \\
\text { deciding the } \\
\text { development } \\
\text { of the com- } \\
\text { pany. }\end{array}$ & $\begin{array}{l}\text { Property right } \\
\text { structure de- } \\
\text { cides the bene- } \\
\text { fits division of } \\
\text { senior mem- } \\
\text { bers. Moreover } \\
\text { it's the pre- } \\
\text { condition of } \\
\text { the harmony in } \\
\text { senior team }\end{array}$ & $\begin{array}{l}\text { Weakness } \\
\text { structure limits } \\
\text { quality of } \\
\text { senior team's } \\
\text { work even } \\
\text { restrain the } \\
\text { develop pro- } \\
\text { gress of the } \\
\text { whole business }\end{array}$ \\
\hline
\end{tabular}

(III) The analysis of private enterprise senior team's function progress.
Private enterprise senior team's function progress determines the installation of establishment and function progress. By studying the progress of senior team, we can achieve the analysis of senior organization's harmony. This kind of analysis goes on through two factors during the function progress. One kind is known factor $\mathrm{K}$, the other is factor $\mathrm{F}$ that can be predicted.

Mathematical formula to:

$C=K\left(k_{1}, k_{2}, k_{3}, \ldots . . k_{n}\right)+F\left(f_{1}, f_{2}, f_{3}, \ldots . . f_{n}\right)$

where $K\left(k_{1}, k_{2}, k_{3}, \ldots . . k_{n}\right)$ for the known factor in the senior team function progress; $k_{1,} k_{2} k_{3}, \ldots . . k_{n}$ for the decentralization and authorizations, the way to set up pundit, decision pattern, inspiration and restriction, information communication market and flat manage, and so on; $F\left(f_{1}, f_{2}, f_{3}, \ldots . . f_{n}\right)$ for the factor that can be predicted during the enterprise senior team function progress; $f_{1}, f_{2}, f_{3}, \ldots . . . f_{n}$ for accidental team's conflicts, senior team's adjustment, senior members' uncertain reactions, the tacit in the team and so on.

\section{The Harmonious Analytical System of Private Enterprises Senior Inte- gration Based on the “ $3 C$ ” system}

The analysis of harmonious integration was divided into five sections based on the“3C”system.

(I) the analysis of structure harmony of private enterprise senior team integration.

The analysis of structure harmony means that analyzing and evaluating comprehensively the harmony degree of the structures between senior team and individuals. The contents of analysis involve four aspects: whether the members enrolled by enterprises are fit for the character of the enterprises' development and satisfy the need of developing; 
whether members' abilities are complementary and can match with each other; whether the property rights structure is reasonable; whether senior team won the fighting against weakness of senior members through the strength of team integration. According to these factors, the analysis of harmony-index involves: the adaptability of senior members to the enterprises, the matching degree among the senior members, the levels of diversity about property rights and the weakness degree of senior leaders.

(II) The analysis of organization harmony of private enterprises senior team integration.

The organization harmony of private enterprises senior team integration means the harmony of the organization design, distributing the rights, coordinating the conflicts, communicating information, inside controlling and so on. The contents to analyze include four aspects: whether division of labor is reasonable; whether they can create an atmosphere of cooperation positively; whether conflicts often happen in senior team; whether senior members exchange information rapidly and timely. According to these factors, the analysis of harmony-index involves: the definition of division, the frequency of dealing with each other among senior members, the frequency of conflicts, as well as the perfect degree of senior information communication system.

(III) The analysis of the internal harmony of the private enterprises senior team integration

If private enterprises senior team structure harmony and organization harmony can be bind to one organic whole by team spirit and enterprise culture, internal harmony of senior team integration in private enterprises will be formed. To reach such a degree of harmony in possibility and fundamental condition, private enterprises has obvious advantages over stateowned enterprises, highlighting in the bu- reaucracy it is not heavy, high team enthusiasm for innovation, enterprises organizational inertia is not strong, the strong sense of mutual respect and cooperation and so on. To analyze the contents involve three aspects.

(IV) The analysis of the exterior harmony of private enterprises senior team integration.

Private enterprises exterior harmony of the senior team integration means an interactive harmony, based on the environmental elements of the development of private enterprises. It involves two aspects that exterior circumstances for its own harmony and the harmony exists between senior team and exterior circumstances for private enterprises. And the latter one is the key to the analysis of external harmony. The analysis can be conducted from the following five factors: whether the structure of senior team adapt to the complexity of the exterior circumstances; whether senior team adapt to the dynamic changes in the exterior circumstances; whether senior team is competent to handle the uncertain challenge of exterior circumstances; whether senior team can grasp the nonlinear law in the exterior circumstances; whether senior team can transform the environment to make it more conductive to the full participation of enterprises in market competition. According to the analysis harmony-index forms: the harmony degree of the environmental concerns of senior members, the parallel harmony degree of senior members' perception about the exterior circumstances, the harmony degree of perfect enterprises early warning mechanism and the harmony degree of the frequency of high-level contacting with other enterprises.

(V) Analysis of overall harmonious integration of private enterprises senior team.

This analysis research the harmony degree of interactive relationship between

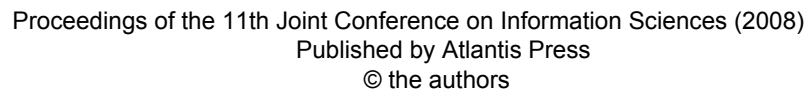


senior team and environment, as well as between senior team and members. It adopts comprehensively the "charactercourse-circumstances” analytical path, absorbing extensively the harmony theory, system theory and upper theory, through structure harmony, organization harmony, internal harmony and exterior harmony evaluation step by step. Consequently we can achieve a general judgment whether the integration of private enterprises senior team is harmonious and what is the harmonious degree. To complete the overall harmonious analysis, we need the help of the sum of four former levels of analysis.

(VI) The construction of harmonious evaluation indicators about the private enterprises senior integration.

We can get the representation model of the evaluation:

$$
\begin{aligned}
& \mathrm{H}=h_{1}\left(h_{11}\left\{h_{111}, h_{112}, h_{113}\right\}, h_{12}\left\{h_{121}, h_{122}\right\}\right. \\
& \left., \quad h_{13}\left\{h_{131}, h_{132}\right\}, h_{14}\left\{h_{141}, h_{142}\right\}\right) \\
& +h_{2}\left(h_{21}\left\{h_{211}, h_{212}\right\}, h_{22}\left\{h_{221}, h_{222}\right\}, h_{23},\right. \\
& \left.h_{24}\left\{h_{241}, h_{242}\right\}\right)+h_{3}\left(h_{31}, h_{32}, h_{33}\right)+ \\
& h_{4}\left(h_{41}, h_{42}, h_{43}, h_{44}\right)=\sum_{\mathrm{j}=1}^{4} \mathrm{~h}_{\mathrm{j}}\left(\mathrm{h}_{\mathrm{jk}}\left(\mathrm{h}_{\mathrm{jkl}}\right)\right)
\end{aligned}
$$

where $\mathrm{j}=1,2,3,4 ; \quad \mathrm{k}=1,2,3,4 ; \quad \mathrm{l}=1,2,3$. When it's the time to assess the general harmony of the private enterprises senior team integration, it can be many integration states in a single private enterprise. Also can be many integration states of a number of private enterprises, or even the same integration state of a number of private enterprises. Here, we should first determine the degree of harmony in each subsystem, and list the harmonious classification table of the subsystem presenting. According to the composition of each subsystem and then further we can get the evaluation indicators and list the degree of harmonious indicators.
Assuming the harmony of private enterprise senior integration is $T_{i}(i=1,2, L n)$. According to the above analysis, we define the evaluation of the state of each element as: $h=h_{j k l}$, where, $\mathrm{j}, \mathrm{k}, \mathrm{l}$ show the target level of harmony element respectively and the meaning of the evaluation is shown in table 2. According to the definition of harmony, a comprehensive evaluation mode is established. The set of factors:

$\mathrm{H}=\mathrm{h}_{\mathrm{jk1}}\left\{\begin{array}{l}\mathrm{j} \mid \text { secondary harmony factors; } \\ \mathrm{k} \mid \text { the third factors; } \\ \mathrm{l} \mid \text { harmonious elements indicators }\end{array}\right\}$

where $\mathrm{j}, \mathrm{k}=1,2,3,4 ; \mathrm{l}=1,2,3$. Set decision: $\mathrm{V}=\left\{\mathrm{v}_{1}, \mathrm{v}_{2}, \mathrm{v}_{3}, \mathrm{v}_{4}\right.$ harmonious degree, $\quad v_{1}=$ considerably harmonious (0.75 1.0), $\quad \mathrm{v}_{2}=$ harmonious(0.5 0.75), $\mathrm{v}_{3}=\mathrm{a}$ little harmonious (0.25 0.50), $\left.\mathrm{V}_{4}=\operatorname{disharmonious}(0 \sim 0.25)\right\}$

So the degree of the overall integration of private enterprises senior can be evaluated by the maximum of $\left\{T_{i-1}, T_{i}, T_{i+1}\right\}$, and also we can evaluate the same factors and the degree of the harmony of the different private enterprises, or compare and analyze the harmony of different period and overall harmony of all levels of the same private enterprise.

\section{Conclusion}

The article is to define the necessity of establishing the analytical system on harmonious integration in private enterprises, induce the model of the analysis of the senior management team integration, reveal the " $3 C$ " analytical path which is based on the harmony of private enterprise seniors, set forth progressively the index system of private enterprise senior team harmony, including analysis of 
structure harmony, analysis of organization harmony, analysis of internal harmony, analysis of external harmony and analysis of overall harmony ,and eventually establish the index evaluation system about the overall harmony degree analysis of private enterprise seniors. These studies offer the method and tools to describe the harmonious status for largescale private enterprise senior team integration in a practical and scientific way, which is of great value.

\section{References}

[1] Bai chong'en, Lu Jiangyong, Tao Zhigang, The Impact on Foreign Enterprises by Investment Environment, Economy Study Journal, 9 pp82-89, 2004

[2] Li Biqiang, Ideas on Complexity of Modern Enterprise System and Management, Chinese Management Science Vol 1 pp332-334, 2002

[3] Lu Rongjie, Xu Wei, Zhang Han, The Construction and Appliance of Dynamic Enterprise Management Model, Science and Technology Management Vol. 9, pp124-127, 2004.

[4] Xi Youmin, Shang Yufan, Harmonious Theory, Chinese People's University, 2002.

[5] Zhang Taisheng, Duan Xinmin, Dynamic and Stable Model of Enterprise Senior Team and Decision Study, Management Science Learned Journal, Volume 6,pp63-68, 2004.

[6] Hebert R F,Albert N. in Search the Meaning of Entrepreneurship. Small Business Economics, 1:39-49, 1989.

[7] S Murshed. Strategic Interaction and Donor Policy Determination. International Review of Economics and Finance. No.3, pp 311-318,2004. 